\title{
First Award of The Charles François International Prize established by IASCYS
}

\author{
Helena KNYAZEVA \\ IASCYS Academician, The Russian Research University \\ Higher School of Economics, Association of Complex \\ Thinking, German Society of Complex Systems and \\ Nonlinear Dynamics, and the Russian Philosophical \\ Society, Board Member of the Bertalanffy Center for the \\ Study of Systems Science, BCSSS, Vienna, Austria \\ helena_knyazeva@mail.ru
}

\section{http://iascys.org}

\author{
Francisco PARRA-LUNA \\ IASCYS Academician, Honorary President Sociedad \\ Española de Sistemas Generales SESGE, Catedrático \\ Universidad de Complutense, Madrid, Spain \\ Parraluna3495@yahoo.es \\ Pierre BRICAGE \\ IASCYS Secretary General, \\ Vice-Président AFSCET, Paris, France \\ http://www.afscet.asso.fr/pagesperso/Bricage.html \\ pierre.bricage@univ-pau.fr
}

\begin{abstract}
This article describes the circumstances of the establishment of the Charles François Prize by the International Academy for Systems and Cybernetic Sciences (IASCYS) and the procedure of its awarding. The role of Charles François's personality, in the development, popularization, and dissemination of systems thinking, the trans-disciplinary methodology of scientific research and the solution of social and practical problems based on it, is shown.
\end{abstract}

Keywords-component: Charles François; cybernetics; International Academy for Systems and Cybernetic Sciences; prize; systemics; systems thinking; trans-disciplinarity.

\section{Introduction (IASCYS)}

The International Academy for Systems and Cybernetic Sciences, IASCYS (uia.org J5273 -Yearbook of International Organizations-, http://iascys.org), was founded in 2010 by the International Federation for Systems Research (IFSR, Vienna, Austria, Europe, http://ifsr.org). Its goals are not only to honor eminent scholars in cybernetics and systems science but also to promote research and education in the systems and cybernetic thinking. The Academy mission consists mainly in strengthening trans-disciplinary interactions between Organizations and Societies working in these fields [1]. This is the purpose of the international prize Charles François as well. The Academy has also as its goal to promote and to encourage educational activities [2], either at the level of its individual member or by organizing workshops during national or international congresses.
As a nonprofit organization, the Academy organizes its activities without receiving any financial support. The Academicians are recruited on competitive examination. They are benevolently working, when respecting the ethics of social responsibility, and namely (in alphabetic order): accountability, conscious reflection, fair governance, fair operating practices, interdependence and holism, compliance with the rules, transparency (ISO 26000 norm). Academicians are not required to assume any specific obligations in their research or education.

\section{The Charles François Prize}

\section{Charles François}

One of the oldest members of the Academy, Charles FRANÇOIS has turned 96 years. Born in Europe, in Belgium, where he got his primary, secondary and university education, he moved then to the depths of 
Africa, the Belgian Congo, where he was engaged in the commercial as well as intellectual activities, being both a journalist and a writer. At the beginning of the process of ending the colonial status in that country, he moved to South America, settling in the Province of Mendoza, Argentina, where he also carried out some commercial activities. His services as a Belgian honorary consul, led him later to the diplomatic activities at the Belgian Embassy in Buenos Aires, as a commercial attaché, until his retirement in 1987.

Then he dedicated his life totally to what was, already for many years, his passion: the study and teaching of General Systems Theory and Cybernetics with its applications to his main interest subjects: economy and education. He spread his knowledge throughout Argentina, various Latin America Countries, and beyond in Europe and the USA. He toured many countries, giving tutorials and lectures, participating in forums and seminars and integrating multiple institutions. He is the author of books, numerous contributions and articles in several languages, and the editor of reference works as a Dictionary in Spanish and the International Encyclopedia in English, both about Systemics and Cybernetics [3].

\section{The Procedure}

In recognition of his outstanding contribution in the development and popularization of the systems thinking, the International Academy for Systems and Cybernetic Sciences has established the Charles François International Prize. The prize has been awarded for a first time during the $10^{\text {th }}$ UES-EUS Congress (http://ueseus.eu), which took place on October 15-17, 2018, in Brussels, Belgium, Europe.

The first step of the procedure was the nomination of interesting papers by asking for the reviewing process by all IASCYS Academicians. So, 6 weeks before the start of the meeting, a booklet of 40 abstracts, previously anonymously peer-reviewed by the scientific committee of the congress, was sent to all Academicians. Each abstract was one page of text without author(s) name(s), their affiliation(s) or any references. After one month of reviewing, 10 abstracts of papers (their topics included Artificial Intelligence, Blockchain, Methods and Tools for Risk Management of Complex Socio-Technical Systems, Professional Systemics Applications) written by researchers from 9 countries (Algeria, Belgium, Denmark, France, Germany, Greece, Italy, Portugal, Russia), were nominated for the Prize by Academicians, by their responses by e-mail. After the organizers of the Congress proposed as a jury a team of three system scientists who speak French and English fluently (these were official languages of the UES-EUS Congress), an equal number of three academicians, who are also fluent in English, French and other languages, was suggested as jury members from the IASCYS. After this key step of pre-selection of peers, the second stage during the meeting in Brussels was for all 6 members of the jury to listen and take part in relevant debates on each of the selected papers, to rate the 3 most promising works, and then to think about the final ranking for the award. It's needless to say that members of jury were anonymous. The audition process consisted of regularly listening to the papers (20 minutes) and discussing the issues raised in them (10 minutes) with participants of workshops, as it is at every congress, as well as of personal informal discussions of the jury members with nominees.

\section{The Laureates}

\section{The Gold Medal}

As a result, the first Charles François International Prize of the Academy (gold medal) was awarded to a young research engineer, Julio LABORDE, who is working about social modeling for the Insight-Signal Company (julio.laborde@insight-signals.com).

Julio Laborde grew in Santiago de Chile, Latin America, where he got a bachelor's degree on Mathematics at the Universidad Catolica. In 2012, he moved to France, where he got a master's degree on Complex Systems, Natural Cognition, and Artificial Intelligence, at the prestigious École Pratique des Hautes Études, EPHE, in Paris, France, where he decided to get a $\mathrm{PhD}$ on Complex Systems. His research is mostly focused on graph theory and pre-topology as tools for the study of Complex Systems. His talk was entitled 'Extraction of Information from Agent Base Models. A new pre-topological metric for controlling the propagation of crises.' His paper was part of the workshop 'Methods and tools for risk management of complex socio-technical systems'. There is no doubt, his work was the most promising work of the Congress of the European Union for Systemics.

\section{The Other Laureates}

The second stage of the awarding procedure consisted in the selection, during discussions, of speakers who took 3 second places, receiving 3 silver medals. The three speakers got the Charles François tutorial in Systems Science [4] on a USB stick, whereas they all, both gold and silver medalists, will have certificates of ranking. However, all of them will get their certificates of award/ranking only after their papers proofs will be corrected and accepted for publication.

These 3 certificated persons, silver medalists, are (by alphabetic order):

- Mick ASHBY, ethics@ashby.de, a research engineer in Computer Sciences who is working for IBM in Germany. He presented a paper about the application of a new paradigm 'The Ethical Regulator Theorem'. Mick Ashby is a Trustee of the American Society for Cybernetics. He studied Computer and Microprocessor Systems at the University of Essex, Colchester, England, where he did research on logics for handling uncertainty. He started working for ITT, Engineering Support Center, Knowledge-Based Systems Group, in Harlow, 
England, developing an AI language for writing expert systems for automating highly-skilled tasks in the telecommunications domains, such as configuring large switching systems and planning the physical layout of telephone exchanges. In 1988, he moved to Alcatel Software Research Center in Stuttgart, Germany, which was the prime-contractor for the EU RACE IOLE research project consortium. As a project manager, he coordinated the consortium's research on requirements and solutions for performing on-line functional extension of broadband telecom software systems. For the past 20 years, he has worked at the IBM Germany Research and Development Lab. in Böblingen. He designed the W. Ross Ashby Digital Archive website. In his spare time, he studies the cybernetics of ethics and publishes the results on his personal website www.ashby.de;

- Tjorven HARMSEN, tjorven.harmsen@leibniz-irs.de, a very young Swedish woman who is doing her Ph.D. thesis at the Leibniz Institute for Society and Space Research (IRS), in Erkner, near Berlin (Germany). Her paper was devoted to 'Crisis as Social Autocatalysis. On the Emergence and Utilization of Opportunities'. This was really a very promising talk of a young researcher who needs to be followed. She works in an empirical project on crisis management and the role of expert advice in the processes of sustainability. She implements an empirical project on crisis management and the role of expert advice in resilience activation processes. Studying sociology at the Universities of Bremen and Jena, Germany, she has developed a interest in systems research. With a focus on some theoretical findings of Niklas Luhmann, she has explored forms of co-evolution of psychic and social systems. To deepen her understanding of system-environment relations and different modes of their observation, she has participated in several activities of the Evolution, Complexity and Cognition (ECCO) research group, Brussels, Belgium; and

- Daniela TERRILE, a woman who is Professor at the Department of Design of the Polytechnic Institute of Milan (Politecnico di Milano), Italy. Her presentation was about 'Applications of the Target Constellation Model'. Daniela Terrile, daniela.terrile@gmail.com, is also a professional coach. HR accredited internal coach, ACC ICF coach, she is working as executive, life and personal development coach. Her interests are in business practice, family and organizational constellation systemic coaching. She uses systemic4all ( ) methodology when studying her clients' strengths and weaknesses, empowering participants, students, managers to face fears and improve their own personal life style. Daniela is thriving when coaching, respecting and adapting to her clients' preferences; she keeps an eye on research to improve her understanding of people's needs, to reveal insights, and to inspire innovative solutions in future management and leadership. She is going to start her PhD stay at Politecnico di Milano on Management. People inspire Daniela; she strongly believes that we have all good vibes, insights and internal resources to be effective and resilient. Her motto is: 'coaching is not about fixing people; coaching is enhancing their potential, in order to help them to gain their space in society and become what they dream to be'.

\section{Comments}

Papers of two other participants were also very interesting but one was not in the book of abstracts (i.e. his paper was not peer-reviewed), the other one was in it, but it was not pre-selected. No procedure is perfect. But the rule is the rule: without peer-reviewing, without pre-selection, it is not possible to take part in competition. The important point is that some of the "pre-selected and nominated, but not occupying a place in the top 3" participants said that they will take part in the next competition for the Prize, in Morocco, in April 2019. And other young researchers said they will do their best to attend another competition for the award.

The Prize has rewarded at the same time 2 'forgotten' confirmed researchers and 2 young 'promising' ones, who bloom or will bloom in multi-cultural, multilingual, inter-disciplinary domains, as Charles François did it, as a pioneer, in his time. At equal skills and quality performance, the preference would be given to such young people, to encourage them in their very difficult path of the trans-disciplinarity.

\section{Conclusion}

The Prize was established to strengthen the multidisciplinary research and the multi-language communication of the latest results, to promote global and widespread education in the field of Cybernetics and Systems Thinking [2], which are at the same time aims of the Academy [1]. Cybernetics and Systems Research has a potential offering a common language and a common vision both to natural sciences and the humanities. The solution of global problems and effective risk management require a combination of phenomenology and theory, of reductionism and holism, for disciplinary deepening in problems and their wide trans-disciplinary coverage [5]. Of particular importance is the application of systems thinking to the modeling of social systems and social forecasting [6].

The final issuance of the prize and certificates, giving evidence of the excellence of the works, is carried out only after the publication of articles in a journal of choice of the organizers. But with the following condition ... According to the professional specificity of Charles François's international way of life, considering the linguistic diversity of the Academicians, the written final text must be at least a bilingual one, a trilingual is better. For example, the complete text can be in English with a very extended summary in French or the opposite. The text, either in French or in English, can be 
Revista Internacional de Sistemas (2019), 23, 1-5

accompanied by an extended summary either in English or in French, another one can be in Spanish or in another language (German, Arabic, Chinese, Portuguese, Russian). "Want to influence the world? Map reveals the best languages to speak." [7].

On the IASCYS website, http://iascys.org, everyone can find the rules of the Prize, currently in English, Spanish, French, and Russian.

\section{REFERENCES}

[1] P. Bricage, "The International Academy for Systems and Cybernetic Sciences“. Rev Intl Sistemas, vol. 19, pp. 1-4, 2014. https://www.uv.es/sesgejd/RIS/19/1.Bricage.IASCYS.pdf

[2] P. Bricage, "Teaching \& Learning Systems Thinking: What, Why, When, Where, Who, What For, How?" Rev Intl Sistemas, vol. 21(1), pp. 9-16, 2017.

https://ojs.uv.es/index.php/ris/article/view/11598/10943
10.7203/RIS.23.1.13759

[3] Ch. François, Editor, The International Encyclopedia of Systems and Cybernetics. Creative Common Internat. Team (ALAS, IASCYS, IFSR), K.G. Saur, München, Germany, 2nd edition, 2 vol., 741 p., 2004.

[4] Ch. François, Tutorial of General Systems Theory \& Cybernetics with Graphic Representations. 1 CD. S. Moriello, Editor, GESI, Buenos Aires, Argentina, 2007.

[5] C. Gershenson, P. Csermely, P. Erdi, H. Knyazeva, and A. Laszlo, A. "The Past, Present and Future of Cybernetics and Systems Research”. Systems. Connecting Matter, Life, Culture and Technology, vol. 1(3), pp. 4-13, 2013.

[6] F. Parra-Luna, "Systems Science and Cybernetics: The Long Road to World Sociosystemicity", in Systems Science and Cybernetics, F. Parra-Luna Editor, EOLSS Publishers Co Ltd, 2009.

[7] S. Ronen, et al., "Links that speak: The global language network and its association with global fame". PNAS, vol. 111(52), pp. E5616-E5622, 2014. http://www.pnas.org/content/111/52/E5616 


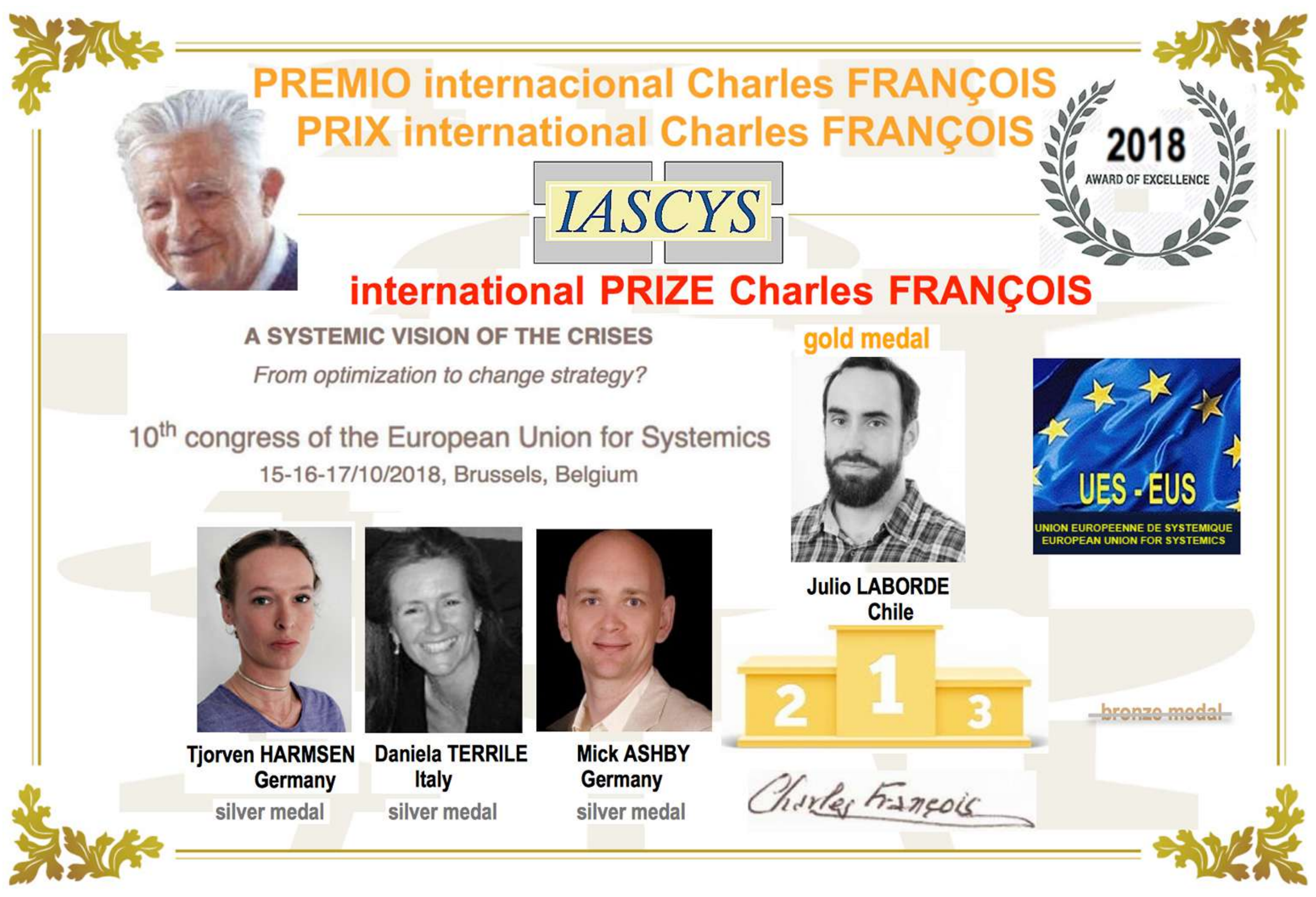

